\title{
ARSIP DIGITAL DI KECAMATAN RUMBAI PESISIR
}

\author{
Yuhelmi1 , Walhidayat2, Rismayeti,3 \\ 1,2,3 Universitas Lancang Kuning, Pekanbaru, Indonesia \\ Jalan Yos Sudarso KM. 08 Rumbai, Pekanbaru-Riau, (0761) 53108 -53236 \\ email ${ }^{1}$ yuhelmi.muchtar@gmail.com, ${ }^{2}$ walhidayat@unilak.a.id, ${ }^{3}$ rismayeti@unilak.ac.id
}

\begin{abstract}
Abstrak: Pengabdian ini dilakukan atas dasar bahwa penulis tergerak setelah melakukan survey ke Kantor Kecamatan Rumbai Pesisir, Penulis melihat masih belum terkelolanya arsip dengan baik dan juga sistem pengarsipan yang belum sesuai dengan standar. Dalam praktik pengelolaan arsip berbasis kertas, banyak permasalahan yang dihadapi, sehingga memberikan ruang pada media elektronik sebagai alternatif dalam pengelolaan arsip. Dalam terminologi kearsipan, media elektronik dikelompokan sebagai arsip media baru. Salah satu bentuk penyimpanan arsip media baru adalah media digital. Media digital biasanya memerlukan alat bantu berupa komputer, karena tidak dapat dibaca secara langsung. Arsip yang disimpan dalam bentuk digital dapat berupa gambar, suara, video, tulisan atau lainnya yang dapat dijadikan sebuah data dalam bentuk biner (binary), dapat diolah dalam program komputer dan disimpan dalam media penyimpanan data digital. Mudah-mudahan dengan adanya pengabdian ini akan menambah ketrampilan mereka dalam hal mendigitalisasikan Arsip dan penggelolaan Arsip dan sistem pengarsipan yang baik sehingga dapat meningkatkan pelayanan Publik. Pengabdian ini akan dilaksanakan untuk Staff di Kecamatan Rumbai Pesisir. Untuk mencapai target luaran kegiatan ini, maka metode yang dilakukan adalah pelatihan kepada mitra. Pelatihan yang diberikan adalah teknik tata cara mendigitalkan Arsip, pengelolaan dan pemberian motivasi untuk bisa memengelola Arsip dengan baik. Rancangan PKM : (1) Sebelum diberikan materi pelatihan peserta diberikan selembar kuesioner untuk melihat kemampuan dan pengetahuan peserta tentang Arsip Digital setelah itu peserta diajak untuk memahami pentingnya pelatihan ini sebagai bekal dalam meningkatkan ketrampilan dan (2) peserta diajak untuk praktik dengan dipandu oleh seorang instruktur yang sudah berpengalaman. (3) Pada tahap terakhir, setelah peserta memiliki ketrampilan dalam mendigitalkan Arsip dan mengelola kearsipan serta bagaimana tata cara penyusunan arsip difilling Kabinet selanjutnya mereka diberikan selembar kuesioner, dari hasil olahan kuesioner dapat dilihat bahwa kemampuan staf meningkat secara signifikan sebesar $64,62 \%$, kemudian dari jumlah peserta yang ditargetkan 10 orang ternyata yang ikut 13 orang, ini menunjukkan bahwa pelatihan ini memang sangat diperlukan staf dalam pekerjaan sehari hari.
\end{abstract}

Kata Kunci: Arsip Digital, Sistem, Manajemen, Arsip, Kecamatan Rumbai Pesisir

\begin{abstract}
This devotion is done on the basis that the author was moved after conducting a survey to the Rumbai Pesisir Sub-District Office, the author sees that the archive is still not managed properly and also the archiving system is not in accordance with the standards. In paper-based records management practices, many problems are faced, thus making room for electronic media as an alternative to archive management. One form of storage of new media archives is digital media. Digital media usually requires computer tools, as they cannot be read directly. Archives stored in digital form can be images, sound, video, writing or other that can be used as a data in binary form, can be processed in computer programs and stored in digital data storage media. Hopefully with this dedication will increase their skills in terms of digitizing archives and managing archives and good archiving systems so as to improve public services. This service will be carried out for Staff in Rumbai Pesisir Subdistrict. To achieve the external target of this activity, the method is training to partners. The training
\end{abstract}


provided is the technique of digitizing the Archives, management and providing motivation to be able to manage the Archives well. PKM design: (1) Before being given the training materials participants were given a questionnaire to see the ability and knowledge of participants about the Digital Archive after which participants were invited to understand the importance of this training as a provision in improving skills and (2) participants were invited to practice with the guidance of an experienced instructor. (3) In the last stage, after participants have skills in digitizing archives and managing archives and how to arrange archives difilling cabinet next they are given a piece of questionnaire, from the results of the questionnaire can be seen that the ability of staff increased significantly by $64.62 \%$, then from the number of participants targeted 10 people turned out to be who participated in 13 people, this shows that this training is really needed staff in daily work.

Keywords: Digital Archive, System, Management, Archives, Rumbai Pesisir Subdistrict

\section{Pendahuluan}

Berawal dari kunjungan tim dosen di Kecamatan Rumbai Pesisir untuk meninjau dan melihat dari dekat penanganan arsip di sana ternyata tim menemukan masih banyak arsip yang belum terkelola dengan baik dimana ketika itu ada salah seorang warga ingin mengurus Kartu Keluarga, disini petugas yang bertugas sedikit bingung untuk mencari arsip yang pernah disimpan, untuk itu tim merasa terpanggil untuk dapat melaksanakan pengabdian Arsip Digital ini agar suasana seperti itu tidak terulang lagi disamping itu juga sekarang semua sudah harus berbasis komputer agar pelayanan dapat ditinggkatkan maka Arsip arssip tersebut harus segera didigitalkan.

Sesuai dengan Undang-Undang RI No. 43 tahun 2009 ketentuan umum bab 1 pasal 1 ayat 15-16 tentang Kearsipan menerangkan :

1. Arsip daerah provinsi adalah lembaga kearsipan berbentuk satuan kerja perangkat daerah yang melaksanakan tugas pemerintahan di bidang kearsipan pemerintahan daerah provinsi yang berkedudukan di ibukota provinsi.

2. Arsip daerah kabupaten/kota adalah lembaga kearsipan berbentuk satuan kerja perangkat daerah yang melaksanakan tugas pemerintahan di bidang kearsipan pemerintahan daerah kabupaten/kota yang berkedudukan di ibukota kabupaten/kota.

Disamping itu tentang penyelenggaraan Kearsipan Kabupaten/Kota menjadi tanggung jawab Pemerintah Daerah/Kota dan dilaksanakan oleh lembaga Kearsipan Kabupaten/Kota, juga dijelaskan pada pasal 24 UU RI No.43 Tahun 2009 tentang Arsip Daerah/Kota sebagai berikut :

1. Arsip daerah kabupaten/kota adalah lembaga kearsipan daerah kabupaten/kota.

2. Pemerintahan daerah kabupaten/kota wajib membentuk arsip daerah kabupaten/kota.

3. Pembentukan arsip daerah kabupaten/kota dilaksanakan sesuai dengan ketentuan peraturan perundang-undangan.

4. Arsip daerah kabupaten/kota sebagaimana dimaksud pada ayat (1) wajib melaksanakan pengelolaan arsip statis yang diterima dari:

a. Satuan kerja perangkat daerah kabupaten/kota dan penyelenggara pemerintahan daerah kabupaten/kota; 
b. Desa atau yang disebut dengan nama lain;

c. Perusahaan;

d. Organisasi politik;

e. Organisasi kemasyarakatan; dan

f. Perseorangan.

\section{Metode}

Kegiatan PKM dilakukan kapada dua mitra yaitu Staf pengelola/petugas kearsipan di kantor Kecamatan Rumbai Pesisir.

\section{a. Pelatihan Penyuluhan tentang Arsip Digital}

Kegiatan pelatihan yang dilakukan pengusul kepada mitra PKM adalah menstransfer informasi tentang tata cara bagaimana mendigitalkan Arsip dan sistem pengarsipan sesuai dengan standar pengelolaan arsip. Pemberian pelayanan kepada masyarakat dan memudahkan staff itu sendiri, faktor-faktor yang mempengaruhi kualitas pelayanan kepada masyarakat antara lain adalah staf/karyawan itu sendiri karena mereka merupakan ujung tombak dari pada pelaksanaan sistem pengarsipan yang baik, dengan PKM ini akan dilakukan paktek mendigitalkan arsip, sistem pengelolaan arsip dan pengarsipan. Pada saat pengusul melakukan survey di lokasi PKM diketahui bahwa para staff belum banyak yang paham bagaimana mendigitalkan arsip dan mengelola dan sistem pengarsipan yang baik. Mereka masih menganggap sepele terhadap arsip yang penting, namun setelah mereka ataupun masyarakat membutuhkan akan arsip tersebut para staf baru sibuk mencari dimana mereka letakkan surat-surat tersebut. Rata-rata mereka tamatan Ilmu administrasi atau Ilmu pemerintahan. Maka dari itu pengusul akan mentransfer informasi kepada mitra dengan mengadakan diskusi tentang pentingnya sebuah arsip dikelola dengan baik, kemudian bagaimana mendigtalkaan arsip, hanya cukup dengan kemauan yang kuat semuanya dapat dilakukan. Materinya adalah:

1. Arsip Digital

2. Sistem Manajemen Arsip

3. Peralatan dan Perlengkapan

4. Komputerisasi Arsip

\section{b. Pelatihan untuk pemahaman}

Dalam pelatihan untuk pemahaman ini mitra di beri pengetahuan tentang Apa itu Arsip Digital dan Kearsipan, bagaimana mengelola arsip digital dari arsip itu diciptakan, didistribusikan, yang diperagakan dan dipresentasikan serta diberikan oleh tim Unilak kepada mitra kemudian dilakukan juga sesi tanya jawab.

Mitra dilatih melakukan pemahaman dahulu agar nantinya tidak sulit dalam sesi simulasi.

\section{c. Pratikum Arsip Digital}

Disini peserta diajak untuk mempraktekan bagaimana mendigitalkan arsip dan apa yang dilakukan dalam mengelola arsip menggunakan komputer mulai dari arsip itu diciptakan, didistribusikan, sampai arsip itu disimpan dengan system penyimpanan yang benar, masing-masing peserta diberi kesempatan untuk dapat mempraktekkannya, sehingga instruktur dapat melihat sampai dimana kemampuan yang sudah dimiliki oleh staff tersebut.

\section{d. Evaluasi hasil.}

Setelah pelatihan juga akan disebar angket untuk melihat pencapaian hasil pelatihan. Evaluasi hasil dapat diketahui dengan membandingkan hasil pretest dan 
postest dari kuesioner yang telah diisi oleh mitra, kemudian diolah untuk dapat disimpulkan.

\section{Hasil dan Pembahasan}

Kegiatan ini dilaksanakan di ruang Kelurahan Limbungan pada tanggal 12 Maret 2020, yang dihadiri oleh 13 peserta, berdasarkan kegiatan yang telah dilaksanakan, beberapa hasil telah diperoleh.

Pada tahap pertama, peserta dibagikan kuesioner pretest untuk diisi peserta setelah itu instruktur menjelaskan teori tentang Pengarsipan dan Arsip Digital serta arahan cara bagaimana melakukan pembuatan arsip digital, sehingga peserta memperoleh pemahaman tentang konsep dasar penarsipan.

Pada tahap kedua, peserta diajak untuk pemahaman terhadap materi yang telah disampaikan dan dipresentasikan oleh Tim Pengabdian, kemudian pada sesi ini juga dibuka sesi tanya jawab terlihat semua peserta antusias untuk bertanya bahkan tim sedikit agak kerepotan dalam melayani yang bertanya mengenai kesulitan yang selama ini mereka hadapi dilapangan untuk mengolahsurat masuk dan keluar sebab selama ini masih menggunakan hard copy yang diarsipkan di lemari arsip. Kemudian Tim Pengabdian menjelaskan salah satunya yaitu dengan berlatih dan praktek sesering mungkin dan dengan sebaik-baiknya,akan mendapatkan hasil yang bagus dan mereka nantinya mampu tanpa harus melihat buku panduan lagi, sehingga dengan demikian mereka akan mampu untuk membuat arsip digital dengan mudah.

Pada tahap terakhir, setelah peserta memiliki ketrampilan dalamproses membuat arsip digital, tim meminta kepada semua peserta yang ikut agar dapat menerapkan ilmunya dan menularkan kepada teman-teman yang tidak bisa ikut pada saat ini.

Setelah peserta memahami dasar-dasar teknik melakukan proses mendigitalkan arsip maka selanjutnya diharapkan dapat melakukan pengolahan arsip, pada tahap ini peserta diminta bagi yang sudah paham untuk dapat memberitahukan kepada peserta lain yang belum begitu mengerti tentang materi yang telah dibahas.

Sesi berikutnya adalah sesi praktik melakukan bagaimana scan surat surat dilakukan dengan menggunakan scanner, setiap peserta diberi kesempatan untuk mempraktekkan langsung kemudian dilanjutkan dengan sharing sesama peserta lainnya.

Sesi terakhir adalah sesi tanya jawab. Pada sesi ini peserta diberikan kesempatan untuk menanyakan dan menanggapi mengenai teori yang telah dipaparkan sebelumnya. Peserta terlihat antusias untuk menanyakan hal-hal yang berkaitan dengan tema pelatihan. Menurut mereka hal ini merupakan sesuatu yang menarik, terutama mengenai kegiatan praktik langsung dipandu dan disimulasikan.

Terakhir tim menyampaikan kepada peserta bahwa ini harus dilatih secara terus menerus untuk memperoleh hasil yang maksimal, jadi suatu pelatihan tidak akan berhasil dan kelihatan hasilnya jika tidak dibarengi dengan kemauan pada masing-masing peserta untuk mau empraktekkan dan menerapkan di linhgkungan kerja. Untuk itu, peserta diberi keyakinan bahwa hasil yang memuaskan tidak akan muncul begitu saja dengan mudah, tetapi diperlukan konsistensi dan keyakinan bahwa sesederhana apapun kegiatan yang dilakukan jika diikuti dengan keyakinan yang kuat maka akan memberikan hasil yang memuaskan.

Evaluasi, ini diperoleh hasil olahan kusioner yakni dengan memberikan kuesioner pada peserta sebelum dan sesudah pelatihan, kemudian dari jawaban kuesioner yang diberikan akan kelihatan perbandingan pengetahuan perserta sebelum dan sesudah pelatihan, lalu ditarik kesimpulan dari hasil yang diperoleh, dari hasil kuisioner tersebut 
dapat diketahui bagaimana pemahaman peserta terhadap materi yang diberikan selama pelatihan.

Untuk lebih jelasnya dapat dilihat hasil rekapitulasi jawaban responden :

Tabel 1. Hasil Rekapitulasi Kuesioner pre test

\begin{tabular}{|l|l|c|c|c|}
\hline No & Item Pertanyaan & Benar & Salah & Kosong \\
\hline 1. & $\begin{array}{l}\text { Apa sebelumnya sudah pernah mendapatkan pelatihan } \\
\text { arsip digital }\end{array}$ & 13 & 0 & 0 \\
\hline 2. & Sebutkan pengertian dari arsip digital & 5 & 4 & 4 \\
\hline 3. & Sebutkan alat yang diperlukan untuk mendigitalisasikan arsip & 0 & 1 & 12 \\
\hline 4. & Sebutkan langkah untuk melakukan digitalisasi arsip & 0 & 0 & 13 \\
\hline 5. & Bagaimana cara temu kembali menggunakan arsip digital & 0 & 0 & 13 \\
\hline & Total & 18 & 5 & 42 \\
\hline & Presentase & $18 / 65^{*}$ & $5 / 65^{*}$ & $42 / 65^{*} 10$ \\
& & $100 \%=$ & $100 \%=$ \\
$27,69 \%$ & $7,69 \%$ & $64,62 \%$ \\
\hline
\end{tabular}

Berdasarkan tabel diatas dapat diketahui bahwa banyak item pertanyaan yang tidak terjawab(kosong) total dari 13 peserta, hanya 18 pertanyaan dijawab dengan benar , 5 pertanyaan dijawab dengan salah dan sebagian besar tidak dijawab yaitu 42 kosong disini dapat kita simpulkan bahwa para peserta masih minim pengetahuannya tentang Arsip Digital.

Untuk item pertanyaan "Sebutkan pengertian arsip digital", dari jawaban kuesioner yang diolah bahwa dari 13 peserta hanya 5 orang jawabanya benar, 4 orang jawabannya salah dan 4 orang tak mengisi jawaban, jadi dapat disimpulkan sebahagian besar belum mengerti apa itu Arsip digital. Tetapi setelah dilakukan pelatihan sebagian besar mengatakan mengerti dengan Arsip digital, ini menunjukan bahwa pelatihan tersebut berhasil.

Selanjutnya untuk item pertanyaan "Sebutkan langkah untuk melakukan digitalisasi arsip", dari 13 peserta satupun tidak ada yang memberikan jawaban (kosong), kemudian setelah dilakukan pelatihan, hampir seluruh dapat menjawab dengan benar, jadi dapat disimpulkan ternyata dari pelatihan yang sederhana ini akan membantu pegawai kecamatan menyelesaikan pekerjaan dengan waktu yang lebih efiisien, dimana dapat dilihat dari hasil olahan kuesioner di bawah ini.

Tabel 2. Hasil Rekapitulasi Kuesioner post test

\begin{tabular}{|c|c|c|c|c|}
\hline No & Item Pertanyaan & Benar & Salah & Kosong \\
\hline 1. & $\begin{array}{l}\text { Apa sebelumnya sudah pernah mendapatkan pelatihan } \\
\text { arsip digital }\end{array}$ & 13 & 0 & 0 \\
\hline 2. & Sebutkan pengertian dari arsip digital & 13 & 0 & 0 \\
\hline 3. & $\begin{array}{l}\text { Sebutkan alat yang diperlukan untuk mendigitalisasikan } \\
\text { arsip }\end{array}$ & 13 & 0 & 0 \\
\hline 4. & Sebutkan langkah untuk melakukan digitalisasi arsip & 10 & 3 & 0 \\
\hline \multirow[t]{3}{*}{5.} & Bagaimana cara temu kembali menggunakan arsip digital & 11 & 0 & 2 \\
\hline & Total & 60 & 3 & 2 \\
\hline & Presentase & $\begin{array}{l}60 / 65 * 100 \% \\
\quad=92 \%\end{array}$ & $\begin{array}{l}3 / 65 * 100 \% \\
=4,62 \%\end{array}$ & $\begin{array}{l}2 / 65 * 100 \% \\
=3,07 \%\end{array}$ \\
\hline
\end{tabular}

Jadi berdasarkan kedua tabel diatas dapat kita lihat meningkatnya kemampuan peserta setelah pelatihan diberikan.

Hasil dari pengabdian ini menunjukkan bahwa Pelatihan yang telah dilaksanakan tersebut berhasil dengan ukuran keberhasilan :

1. Jumlah peserta melebihi kuota yang tersedia yaitu 13 orang peserta. (dapat dilihat 
daftar hadir)

2. Hasil olahan data ( pre test dan post tes) menunjukan peningkatan kemampuan peserta (dapat dilihat pada pembahasan)

\section{Kesimpulan}

Setelah pengabdian ini dilaksanakan dan data kuesioner sudah diolah pengetahuan dan keahlian peserta mengalami peningkatan, dimana pengetahuan peserta naik secara signifikan sebesar $64,62 \%$ yaitu sebelum pelatihan $27,69 \%$ setelah pelatihan dilaksanakan menjadi $92,31 \%$.

\section{Ucapan Terima Kasih}

Terima akasih kepada Fakultas IImu Komputer Universitas Lancang Kuning yang telah membantu secara financial dalam pelaksanaan kegiatan Pengabdian Kepada Masyarakat ini

\section{Daftar Pustaka}

Adi Putranto Widiatmoko, 2017, Pengelolaan Arsip Di Era Digital: Mempertimbangkan Kembali Sudut Pandang https://jurnal.ugm.ac.id/diplomatika/article/view/28253

Dwiyanto, Agus. 2011. Manajemen Pelayanan Publik: Peduli, Inklusif dan Kolaboratif Yogyakarta: Gadjah Mada University Press.

Ismail, A., \& Jamaludin, A. (2009). "Towards establishing a framework for managing trusted records in the electronic environment" in Records Management Journal, $19(2), 135-146$.

Johnston, G. P., \& Bowen, D. V. (2005). "The benefits of electronic records management systems: A general review of published and some unpublished cases" in Records Management Journal, 15(3), 131-175.

Kallberg, M. (2012). "Archivists 2.0: redefining the archivist's profession in the digital age" in Records Management Journal, 22(2), 98-115.

Permen No. 78 tahun 2012 tentang Tata Kearsipan Departemen Dalam Negeri dan Pemerintah Daerah.

Sugiharto Dhani, jurnal Baca Vol. 31, No. 1, Agustus 2010 (51 - 64) Penyelamatan Informasi Dokumen/Arsip Di Era Teknologi Digital file://C:/Users/toshiba/Downloads/96-188-1-SM\%20(1).pdf

Sambas Ali Muhidin, Hendri Winata, Budi Santoso, 2016, Journal Pendidikan Bisnis dan Manajemen, Pengelolaan Arsip Digital, vol. 2 no. 3 November 2016, http://journal2.um.ac.id/index.php/jpbm/article/view/1708

Undang-Undang RI Nomor 43 Tahun 2009, tentang Kearsipan.

Yuhelmi, 2014.Analisis Kualitas Pelayanan PublikBadan Perpustakaan Dan Arsip Daerah Provinsi Riau, Jurnal Lectura Vol. 5 No. 2 Hal.176 